Res Pública Revista de Historia de las Ideas Políticas

ISSN: $1131-558 \mathrm{X}$

https://dx.doi.org/10.5209/rpub.75986

\title{
De lo vampírico a lo salvaje: mordida y política de las relaciones de producción capitalistas
}

\author{
Matías Beverinotti ${ }^{1}$
}

Recibido: 08-05-2021 / Aceptado: 08-09-2021

\begin{abstract}
Resumen. En República salvaje, Jacques Lezra vuelve a Lucrecio para repensar la república frente al desconcierto antidemocrático de nuestro tiempo. La política de Lucrecio nos permite pensar lo político en el encuentro con el otro, en lo aleatorio, en lo casual: pensar la república a partir del encuentro material. Lezra apelará a Lucrecio para abrir la posibilidad de crear una soberanía de lo múltiple correspondiente a una república salvaje. Como analogía de ello Lezra propone la mordida entre amantes o defectiva como la piensa Jacques Derrida, como sexto sentido cuya des-jerarquización y horizontalidad igualitaria es análoga al sexo atómico lucreciano. Lo que veremos aquí es cómo esta mordida es la metáfora de una relación política otra, superadora del autoritarismo fascista y antidemocrático de contexto, producido por el devenir de la axiomática de las relaciones de producción capitalistas que se manifiesta de forma vampírica según Marx.
\end{abstract}

Palabras claves: Lucrecio; Marx; República; Mordida; Vampiro.

\section{[en] From Vampirism to Savagery: Biting and the Politics of Capitalist Productive Relations}

\begin{abstract}
In República salvaje, Jacques Lezra returns to Lucretius to re-think the republic against the anti-democratic political context of our times. Lucretius' politics allow us to think the material aspect of the encounter with others, in order to think the republic from its materiality. Lezra appeals to Lucretius in order to open the possibility to create a multiple sovereignty that corresponds to a savage republic. As an analogy of this Republic, Lezra suggests the defective biting between lovers as Jacques Derrida understands it, as a sixth sense whose de-organizing and horizontalizing power is analogous to the Lucretian atomic sex. This article analyses how this biting is the metaphor of a political relation that overcomes the fascism of our times, which is the result of the way the capitalist axiomatic productive relations are organized as a vampire-like power structure in the words of Marx.
\end{abstract}

Keywords: Lucretius; Marx; Republic; Bite; Vampire.

Sumario. 1. El jardín no es el bosque: de Epicuro a Lucrecio. 2. Materialismo aleatorio y axiomática capitalista. 3. Mordida y capitalismo. Bibliografía.

Cómo citar: Beverinotti, M. (2022). De lo vampírico a lo salvaje: mordida y política de las relaciones de producción capitalistas. Res Pública. Revista de Historia de las Ideas Políticas, 25(2), 49-57.

En el último libro de Jacques Lezra, República salvaje, el autor vuelve al pensamiento atómico de Lucrecio y de la naturaleza de las cosas en De rerum natura. ¿Cuál es la función y qué pretende Lezra con volver a Lucrecio? ¿Por qué retomar un poema de más de dos mil años de antigüedad? Lezra nos explica que Lucrecio y su De rerum natura develan elementos claves para reemprender un pensamiento sobre la república en pos de desafiar al galopante ascenso global del fascismo neoliberal de las últimas décadas. En otras palabras, frente al desesperante contexto en el que -parafraseando a el título acuñado por Sergio Villalobos-Ruminott, el fascismo asedia-, el repensar la república significa volver a interrogar la cuestión comunitaria, igualitaria e indetermi- nada del ser-con-los-otros, del ser-en-común, de cómo establecer bases más solidas del compartir cotidiano que hemos visto extinguirse a fuego lento, en el caso que ellas alguna vez hayan existido. Entonces el objetivo del libro es repensar no la república, sino el republicanismo, en el momento que los universales de la política moderna sólo encuentran su fuerza representativa y articulatoria en la derecha fascista. ¿Cómo hacer surgir de esto, un nuevo ser-con-los-otros? Repensar la república es repensar la política en un contexto donde lo político devela su agotamiento. La puesta en escena de la poética de Lucrecio tiene una demanda implícita que es el desafío de encontrar la forma de un pensamiento no-jerárquico de lo múltiple, que sería en palabras de Alain Badiou, la 
cuestión de la ontología del comunismo². Es a esto a lo que Lezra llama república salvaje o material, al volver a hacer una ontología de lo común para ver cómo se puede rehacer el ser-en-común. Dicho de otro modo, el objetivo es la construcción de “...una república que no tiende a lo Uno"3, sino a lo múltiple que hace al ser-en-común de la ontología del comunismo, a otro ser-con-los-otros igualitario y democrático, y por ello indeterminado en su propio devenir, más allá del galopante fascismo neoliberal. Lucrecio nos brinda la posibilidad de repensar la ontología de las relaciones, que sería donde está en juego lo salvaje a lo que apunta Lezra: específicamente, de las relaciones políticas, que son las que deforman las auto-identificaciones para generar un devenir otro intersubjetivo e indeterminado. Lucrecio nos brindaría entonces, la clave de la república por venir: una república material, salvaje.

Si el problema es el fascismo que deviene como primogénito del capitalismo neoliberal a escala global, la cuestión de fondo será cómo cambiar las relaciones sociales cuando devienen en violencia desenmascarada, por otras que sean -vulgarmente hablando- compartidas, equitativas, abiertas a lo aleatorio, igualitarias, múltiples, etc. El problema es, cómo generar “....un tipo de republicanismo, de asociación, de formalización de las relaciones sociales que no se basa en conceptos fundamentales -o Grundbegriffe si se quiere-" mentablemente no lo desarrolla en el libro, Lezra propone para esto a un sexto sentido como el objetivo de esta república salvaje: la mordida, que Jacques Derrida problematiza en su seminario inédito "Manger l'autre: Politiques de l'amitié" (1990-1991)5. Esta mordida representa el querer consumirse entre amantes, lo que develaría según Lezra, la clave del sexo atómico lucreciano. Ello muestra una relación igualitaria y compartida, constituido a partir de una "política del sentir y de lo sensible" $"$ No es ésta la mordida hecha para consumir al otro, sino de hacerlo mutuamente: "Hay una mordida mutua...la mera mordida es el sexo atómico"7. Será este sexto sentido el que devela la relación con-los-otros de la manera a la que apuntaría la materialidad de la república salvaje, siendo clave para salir de la presente alza del fascismo mostrando una relación diferente entre individuos. El orden político que piensa Lezra, basándose en Lucrecio, es uno que altera y modifica las relaciones entre los átomos desplegado en el presente neoliberal, que propone un encuentro otro más allá del consumo del otro. Lo que nos permite esta conclusión del autor, es ver por un lado que se abre un diálogo subterráneo alrededor de la mordida como analogía de las relaciones sociales, y específicamente, sobre las relaciones de producción. Se nos hace imposible entonces, disociar el problema

\footnotetext{
J. Lezra, República salvaje, Santiago de Chile, Ediciones Macul, 2019 , p. 26.

Ibidem, p. 70.

Ibidem, p. 296

Este seminario en realidad es parte de un proyecto mayor en el que Derrida trabaja durante más de dos años que suma dos secciones de clases sobre comer al otro y que son consecuencias de una serie de clases anteriores, tituladas "Rhétorique du cannibalisme".

J. Lezra, República salvaje, op. cit. pp. 51.

Ibidem, pp. 174-5.
}

comunitario como crítica al fascismo, de las relaciones que impone el sistema de acumulación de valor. Muere aquí, como dice Sergio Villalobos-Ruminott, la falsa homologación entre democracia y capitalismo para entender que las relaciones sociales propuestas por la gobernabilidad neoliberal componen un individualismo competitivo, reduccionista y utilitario que deriva en su propio fascismo, que es donde estamos domicialiados ${ }^{8}$. Si como dice Lezra, el objetivo de República salvaje es analizar las relaciones entre los cuerpos en tanto entes políticos, el análisis de la mordida aparece como posible analogía ${ }^{9}$, en especial en su crítica a las relaciones de producción y acumulación en su función a-política. El objetivo entonces es analizar, ¿cómo la mordida describe la forma de nuestras relaciones sociales de producción? Y, ¿cómo ella, como propone Lezra, puede también ser la clave para crear lo común más allá de la estructura fascista en alza?

\section{El jardín no es el bosque: de Epicuro a Lucrecio}

La primera tarea que se toma Lezra en República salvaje es dar un recuento de las diferencias cualitativas entre el pensamiento de Lucrecio y el de Epicuro, teniendo la metáfora del jardín del último como centro. Es en ese jardín -explica Lezra- donde Epicuro ambienta la producción o inducción del placer catastemático. El jardín es un espacio que se encuentra de espaldas a la ciudad y por ello a la política. Es el que funciona como base para el placer continuo, la llave para arribar a la autarquía. El jardín es entonces el lugar que permite un habitar el mundo en busca del equilibrio continuo, producido necesariamente más allá de la ciudad. El objetivo del placer catastemático será entonces llegar a un tipo de serenidad que convierte al filósofo en espectador, al abandonar su intervención en el mundo ${ }^{10}$. Esto hace de la teoría de Epicuro una sin tacto: "Para él la labor que existe es simplemente la de ser espectador, y de ver lo que pasa, y de darnos la teoría de lo que pasa, sin poder intervenir" ${ }^{11}$. El placer catastemático depende de este espacio donde se logra un placer in-tacto, habitado en el otium, cuando el mundo es de contacto.

Por el contrario, el pensamiento de Lucrecio trata de lo discontinuo, de la formación de un ser-en-común anacrónico y extemporáneo. Esto hace que el problema principal en De rerum natura sea el de las relaciones entre los humanos, cuyo frágil equilibrio nos obliga a abandonar el problema del equilibrado y continuo placer catastemático. Lucrecio basa su pensamiento en la relación política entre las personas, en su disenso, en lo casual de su encuentro aleatorio. Será por ello por lo que el pensamiento de Lucrecio necesita descartar la búsqueda epicúrea del placer individual, en un territorio

S. Villalobos-Ruminott, Asedios al fascismo, Santiago de Chile, DobleAEditores, 2020, capítulo 1.

J. Lezra, República salvaje, op. cit. pp. 31-2.

10 Lezra recuerda el ejemplo de Epicuro cuando explica esta desenvoltura a un filósofo que no ayuda a una persona que se está ahogando. El placer catastemático deja que el mundo sea en su propia inmanencia.

11 J. Lezra, República salvaje, op. cit. p. 130. 
que tiene la pretensión de deshacerse del encuentro y de lo aleatorio, lo que lo hace un pensamiento más asociado al bosque que al jardín. Lucrecio cambia la contemplación clásica de lo político por el encuentro que demanda la política, lo que devela lo defectivo -término que Lezra acuña- de la subjetividad, de las instituciones, de las soberanías. Ello no se da ni puede darse en el jardín. Por el contrario, el jardín es donde este encuentro queda relegado. En breve, el problema de De rerum natura es la relación y asociación de los seres humanos más allá del jardín de Epicuro. El salto cualitativo de Lucrecio con respecto a Epicuro es el de cambiar el centro del pensamiento del otium al negotium.

El pensamiento de Lucrecio es entonces uno de límites, del terminus, pero de cuando ellos se negocian. Por el contrario, el pensamiento de Epicuro sólo puede ser cuando este terminus ya ha sido negociado. Por lo tanto, el problema de la república es para Lezra, el "... problema del borde, lo podemos tomar como el problema de la superficie, y por tanto, como el problema del tacto...república y materia...república material. ¿Sobre qué tipo de base se puede construir una relación con otros, una relación republicana?" 12 . La soberanía, la política y por ello la solución al presente fascista, es de las relaciones intersubjetivas entre los cuerpos. Será por esta razón que Lucrecio centra su pensamiento en lo material, en lo aleatorio, ya que lo que importa a fin de cuentas es el análisis de cómo se negocia la comunidad: su terminus en común. Esto da espacio a enfatizar lo aleatorio del encuentro que nos abre a "Una versión pluralista del republicanismo..." donde las instituciones son lo suficientemente flexibles o defectivas para lidiar con este encuentro en lugar de apuntar a lo continuo entendido como orden, generalmente conservado por la violencia. Para ello, Lucrecio recae en el pensamiento sobre la relación material de los átomos, que explicaría tanto las relaciones materiales entre sujetos como también cómo ellas forman su subjetividad e identidad.

\section{Materialismo aleatorio y axiomática capitalista}

A principios de los años ochenta, luego de batallar con serios problemas de salud, Louis Althusser retoma la escritura de un manuscrito inacabado, publicado más tarde con el título "Le courant souterrain du matérialisme de la recontre". Aquí, Althusser descubre una corriente subterránea del materialismo del encuentro, en la que hallamos a Marx, Derrida, Heidegger, Spinoza y, por supuesto, a Lucrecio. La metáfora que usa Althusser para explicar este materialismo es la del encuentro de dos gotas de lluvia. En la lluvia, las gotas se encuentran con la misma irregularidad y de la misma forma inesperada que la declinación o clinamen de los átomos en el pensamiento de Lucrecio $^{13}$. La caída paralela de los átomos, análoga a las de las gotas de lluvia, se ve interrumpida por el encuentro inesperado. Lo que prima es

Ibidem, p. 162 .

13 L. Althusser, Para un materialismo aleatorio, trad. P. Férnandez Lira, L. Alegre Zahonero y G. González Diéguez, Madrid, Arena, 2002, p. 31. lo material y lo aleatorio. Esta idea Althusser la toma de Nicolás Malebranche, quien no sólo observa el encuentro aleatorio sino también que la contingencia material tiene un aspecto formativo, ya que prepara el alma para otra lluvia ${ }^{14}$.

El clinamen es un misterio: nadie sabe cómo sucede ni dónde ni cuándo, pero lo que sabemos es que está ahí y es un eventum ${ }^{15}$. Es la desviación de los átomos que termina siendo no del todo clara ni evidente, ya que esta inclinación parece ser inmotivada ${ }^{16}$. Lo que Lucrecio pretende es hacer de lo aleatorio, algo motivado, es decir, interrumpir lo simétricamente determinado. Althusser menciona que esto se formula en diferentes teorías filosóficas: desde el es gibt heideggeriano ${ }^{17}$ hasta el pensamiento político de Maquiavelo, pasando por Spinoza. Pero lo principal es que en la corriente subterránea que traza Althusser, reconoce en el clinamen o la desviación aleatoria de los átomos, el inicio de una reacción en cadena que compone el mundo. Esto es radicalmente diferente a las tradiciones filosóficas que encuentran el origen en la razón, la esencia o la causa. Al mismo tiempo, este encuentro es un encadenamiento de hechos aleatorios en donde el sujeto no es un fundamento material, sino que queda dominado por el advenimiento de un desarrollo sin fin $^{18}$. Para Lucrecio, este encuentro es un evento que forma nuevas formas, donde prima el encuentro y no una forma previa a él ${ }^{19}$. Todo encuentro aleatorio tiene consecuencias aleatorias, indefinidas. Esto le sirve al filósofo francés para ver cómo se da ese encuentro, en el modo de producción capitalista ${ }^{20}$.

Desde la visión del materialismo del encuentro, Althusser plantea el pensamiento de Marx respecto al modo de producción capitalista: "En innumerables pasajes, y no precisamente por azar, Marx nos explica que el modo de producción capitalista ha nacido del encuentro entre los «hombres de escudos» y el proletario desprovisto de todo menos de su fuerza de trabajo" 21 . Por supuesto que este encuentro, para Marx, no es necesariamente aleatorio. Por el contrario, es la consecuencia material de una suma de consecuencias histórico-materiales que preparan este encuentro y lo vuelven inevitable $^{22}$. El encuentro entre el poseedor de capital y quien sólo posee su fuerza de trabajo que se vuelve mercancía, es la consecuencia de una larga historia de desposeimiento en el que este encuentro se vuelve consecuencia. En este sentido, tanto Marx como Althusser, verán que

\footnotetext{
L. Althusser, "The Underground current", Philosophy of the Encounter, trad. G. M. Goshgarian, New York, Verso, p. 204. La versión en español del texto hace referencia a esta idea al texto Entretiens sur la métaphysique de Malebranche, mientras la traducción al inglés también hará referencia a Traité de la nature et de la grâce de donde sacan la siguiente cita en traducida al inglés: "I use the examples of the irregularity of ordinary rain to ready the soul for another rain, which is not given to the merits of men".

5 J. Lezra, República salvaje, op. cit. p. 128.

16 W. Motte, "Clinamen Redux" Comparative Literature Studies, 23, 4, 1986, p. 264.

L. Althusser, Para un materialismo aleatorio, op. cit. p. 35.

Ibidem, p. 57.

Ibidem, p. 58

Ibidem, p. 64.

Idem.

22 S. Mezzadra, La cocina de Marx. El sujeto y su producción, trad. D. Picotto, Buenos Aires, Tinta Limón, 2014, p. 87.
} 
no son sólo los factores económicos los que fuerzan este encuentro, sino también otros como los políticos, legales o ideológicos.

Podríamos arriesgar a decir que la historia material del capital no sólo deriva en este encuentro que aparece como legalmente igualitario, avalado y forjado en un contrato entre los que pactan la venta y compra de fuerza de trabajo ${ }^{23}$. También la historia material del capital nos mostrará que su estrategia más evidente es la de reforzar, intensificar y solidificar esta relación desigual entre roles determinados o personificaciones de categorías económicas en la que cada sujeto actúa como su portador (Träger). El movimiento que observa Marx en el desarrollo del capital según Althusser, es que en su devenir fija las relaciones desiguales de producción, ya que depende de ellas para reproducirse. La relación de explotación “...resume en sí misma, neutralizándolas, un conjunto de relaciones políticas de dominación, encerrándolas al trabajo vivo en una estrechísima malla, disciplinando la excedencia para volverla productiva (de plusvalía)"24. Este encuentro entonces es necesario para la producción de plus-valor. Lo que buscará hacer el capitalismo es conservar constantemente suturando este encuentro en las relaciones de producción entre explotador y explotado. La economía, las leyes, la propiedad, la ideología solidifican esta relación: de ella dependen. Las relaciones de producción tienden entonces, a la "Producción y reproducción de la relación" 25 , a reiterar las condiciones que hicieron posible ese encuentro, sean o no económicas.

La reproducción del modo de producción capitalista es un modo de "doble combinación" que consta de la reproducción tanto de los medios de producción y de las relaciones de producción ${ }^{26}$. Sin embargo, lo que vemos en la explicación de Marx es que el encuentro entre comprador y vendedor de fuerza de trabajo no es sólo una consecuencia histórico-material, sino que al mismo tiempo el capitalismo crea diferentes elementos para que ese encuentro nunca sea alterado por otro: para reproducir las relaciones de producción, es necesario reproducirlas sin diferencia ${ }^{27}$. Althusser explicará la reproducción de las relaciones de explotación por la superestructura que componen principalmente los aparatos ideológicos del Estado, que al mismo tiempo impiden la formación de relaciones nuevas ${ }^{28}$. Lo que se garantiza entonces es la reproducción de un sistema de explotación gracias a un entramado ideológico, legal-político e institucional ${ }^{29}$ que, parafraseando a Lezra, pretende ser in-defectivo en pos de su reproducción infinita de las fuerzas productivas. El devenir del capital ha determinado estas relaciones y las ha hecho determinadas y determinantes,

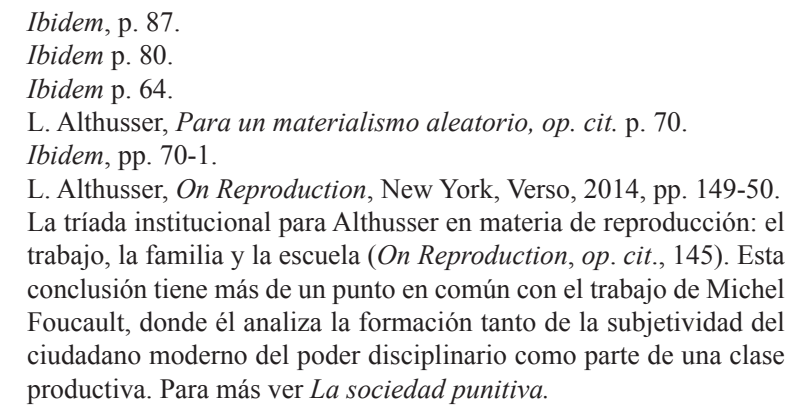

haciendo de la relación misma la que está en juego en la reproducción del capital, siendo ella lo esencial al hombre y no la idea o la abstracción religiosa, como explica Marx en su sexta Tesis sobre Feuerbach: "Feuerbach diluye la esencia religiosa en la esencia humana. Pero la esencia humana no es algo abstracto inherente a cada individuo. Es, en su realidad, el conjunto de las relaciones sociales" ${ }^{30}$. La relación de producción entre obrero y capitalista sigue el devenir inmanente que propone Deleuze al categorizar a las relaciones de producción capitalistas como una axiomática.

Para Deleuze, la relación de producción es el encuentro en la relación diferencial entre los flujos del capital y el flujo del trabajo ${ }^{31}$. El encuentro entre ambos es necesario para que ambos se reproduzcan. En caso contrario, serán solamente virtuales. Lo que sucede, a fin de cuentas, es que ambos “....están presos en relaciones de determinación recíproca, al punto que ninguno es determinable fuera de la relación diferencial que tienen con el otro" "32. Marx llamará a esto una relación de voluntades que, aunque opuestas, igualan la misma voluntad:

...a apropiarse de la mercancía ajena al enajenar la propia. Los dos, por consiguiente, deben reconocerse uno al otro como propietarios privados. Esta relación jurídica, cuya forma es el contrato -legalmente formulado o no-, es una relación entre voluntades en las que se refleja la relación económica. El contenido de tal relación jurídica o entre voluntades queda dado por la relación económica misma. Aquí las personas sólo existen unas para las otras como representantes de la mercancía, y por ende como poseedores de mercancias ${ }^{33}$.

Por lo tanto, hay una igualdad contractual de voluntades, una equivalencia determinada en el encuentro de intercambio de mercancías para satisfacer necesidades propias $^{34}$. Sin embargo, lo que deja en claro Deleuze es que la relación entre explotador y explotado en el modo de producción capitalista, no sólo es la consecuencia de su propia deriva histórico-material, sino que al mismo tiempo este encuentro enlaza voluntades iguales según Marx o flujos según Deleuze, casi atenazándolos, impidiéndoles otros encuentros. Se subraya el encuentro, pero se impide lo aleatorio. La axiomática es la composición de relaciones diferenciales entre flujos que determina a cada uno de ellos ${ }^{35}$, que en nuestro caso lo vuelve un juego de doble dependencia. Ella es determinante a la producción del sujeto de producción y a su enajenación. Es por lo que el pensamiento de Marx puede ser leído como el llamado a una nueva "ontología de las relaciones"36, funcional a cambiar estas relaciones determinadas, a hacerlas defectivas.

La axiomática que establece la relación diferencial de flujos genera también su propia inmanencia en su mu-

\footnotetext{
https://www.marxists.org/espanol/m-e/1840s/45-feuer.htm

G. Deleuze, Derrames I. Entre el capitalismo y la esquizofrenia, Buenos Aires, Editorial Cactus, p. 98.

32 Ibidem, p. 102.

33 K, Marx, El Capital Tomo I Vol. I, Iztapalapa, Siglo XXI, 2018, pp. 103-4.

34 Ibidem, p. 105

35 G. Deleuze, op. cit., p. 122

36 Mezzadra, op. cit., p. 40.
} 
tua dependencia. La apropiación de la fuerza productiva de uno por otro es una relación de poder: es extra-económica $^{37}$, en la que se juegan también -como veníamos diciendo-subconjuntos de aplicaciones que fuerzan esta doble dependencia a pesar de su inmanencia. La reproducción de esta axiomática según Deleuze, se divide en dos: humana y social. La primera es, por ejemplo, la de la filiación familiar, que es de segundo orden en el modo de producción capitalista. La segunda, en cambio, es la que produce imágenes y roles impuestos en la sociedad capitalista: "...el capitalista, el industrial, el banquero, el trabajador" 38 . La religión asegura la producción de imágenes para la reproducción social, aunque la principal característica de la axiomática es que no depende del elemento extrínseco para justificar sus relaciones diferenciales $^{39}$, ya que en su estructura sólo devela la fuerza de la pulsión de muerte. Dicho de otro modo, la axiomática capitalista se libera de la necesidad que tiene el sistema de códigos -el soberano, por ejemplo- de legitimar las relaciones de poder por la presencia material de una ausencia extrínseca a sus relaciones: por ejemplo, Dios. Las relaciones de producción capitalistas están legitimadas en la relación misma, en su propia atadura, que está movilizada por la pulsión de muerte. Lo que se preguntará Lezra en este caso es cómo hacer que estos roles terminen siendo defectivos para así volver a introducir la aleatoriedad en las relaciones sociales.

La condición histórico-material para que esta axiomática exista es la libertad del trabajo, al que Deleuze le agregará al psicoanálisis una responsabilidad crucial en la reproducción de estas relaciones de explotación. Lo que propone el filósofo francés en sus trabajos con Felix Guattari, serán formas por y en las cuales esta axiomática que disciplina el deseo por la estructura edípica, sea liberada, aunque siempre con la advertencia de no crear relaciones de producción que sean peores a las conocidas. Ello podría potencialmente suceder, si hubiese un cambio radical en la forma en la que el psicoanálisis opera. Esto generaría un cambio al transformarlo de una de las armas por excelencia que tiene el capitalismo para su reproducción social, a las dos soluciones que propone Leclaire $^{40}$ : Primero: que el psicoanálisis deje de ser la inculcación de una axiomática de otra naturaleza a lo real. ¿Cómo se logra esto? Segundo: volviendo a poner al psicoanálisis en comunicación con lo real, o como dice Deleuze: "el psicoanálisis debe morder lo real" No nos detendremos en las complejidades que el psicoanálisis quiere decir o no con el término "real", pero sí en la cuestión de cómo vuelve a aparecer en escena, como en el libro de Lezra, la metáfora de la mordida como ruptura de esta relación diferencial.

\footnotetext{
G. Deleuze, op. cit., p. 126.

Ibidem, pp. 134-5.

Ibidem, p. 138.

40 Deleuze crítica a Freud y su psicoanálisis en Derrames I. Para él, el psicoanálisis ha cumplido esta función, más allá que los primeros textos de Freud, especialmente en "Tres ensayos sobre la teoría sexual", problematiza el disciplinamiento del flujo. Sin embargo, sus textos posteriores generan imágenes y relaciones diferenciales para normalizarlos en su función capitalista. Para más ver "Clase VIII: Economía y psicoanálisis, más allá del paralelismo", Derrames I.
}

41 G. Deleuze, op. cit. p. 149.
En breve, la mordida devela el encuentro de las relaciones diferenciales de producción del modo de producción capitalista. Ya sea en el caso de Deleuze que propone una mordida que muerda lo real o como dice Lezra, que sea una mordida mutua entre amantes que es análoga al sexo atómico lucreciano que nos atrevemos a llamar "mordida defectiva", lo que vemos es que en ambos casos se trata de una mordida que aparece como llave de superación a la problemática de las relaciones de producción determinada por el modo de producción capitalista. ¿Por qué? ¿Hay una mordida anterior que se quiere superar por una nueva? ¿Qué otra mordida es la que se quiere contrarrestar o superar? Estos son los interrogantes que guían la siguiente sección.

\section{Mordida y capitalismo}

Como hemos apuntado anteriormente, la cuestión de la mordida es más insinuada que tratada en República salvaje. Sin embargo, en 1996, Lezra publicó un artículo titulado "Odontologies", donde piensa la relación entre la representación de la boca y la ilustración, en especial con su conexión con el alcance de la mayoría de edad en las pinturas de Goya. Sin embargo, en este artículo Lezra no trata la cuestión de la mordida y su vínculo a la organización de las relaciones de poder. El ejemplo por excelencia de este tema en las pinturas de Goya ${ }^{42}$ sería Saturno devorando a su hijo -al que Lezra no hace alusión-, donde la mordida actúa como el aniquilamiento del otro con el fin que siga reproduciéndose la misma organización y estructura del poder. También se indaga aquí sobre la reproducción de la vida y la continuidad del linaje, dos temas que en el modo de producción capitalista son reproducidas de manera diferente al régimen que critica Goya. En otras palabras, la axiomática de las relaciones de producción capitalista demanda en su mutua atadura por su necesidad de reproducción, el no aniquilamiento del sujeto explotado o del súbdito. Por el contrario, lo que se ejerce en estas relaciones es notablemente diferente a lo que hace Saturno, ya que lo que se pretende es solidificar esta relación que se vive como encuentro, donde la subsistencia de esta axiomática demanda la supervivencia de ambos polos del contrato para reanudar el encuentro original ad infinitum: "Su mera continuidad...reproduce y perpetúa ese punto de partida del proceso como resultado del mismo"43. Por otro lado, quizá podríamos hacer un paralelo por lo Lezra quiere decir en República salvaje acerca de la mordida entre amantes con lo que él dice sobre los vínculos políticos en su artículo "Relation". Lo político de las relaciones que según Lezra, tomando a Simondon, demandaría la deformación y formalización de las relaciones interindividuales para salirse de la auto-identificación para abrirse hacia lo indefinido ${ }^{44}$. En otras palabras, la política a

\footnotetext{
2 J. Lezra "Odontologies", en A. Weinyer y L. Kaplan (eds.), Madness, Melancholy and the Limits of the Self Graven Images 3, 1996, p. 93. 43 K, Marx, El Capital Tomo I Vol. II, Iztapalapa, Siglo XXI, 2017, p. 701.

44 J. Lezra, "Relation", en J. Lezra, A. L. Stoler, G. Stathis (eds.), Thinking with Balibar: a Lexicon of Conceptual Practice New York, Fordham UP, 2020 pp. 215-6.
} 
la que apunta Lezra de la mordida entre amantes es la que desestabiliza las relaciones y los roles sociales, y de ellos con las instituciones, más allá de la fijación de roles determinados de las relaciones de producción y lo apolítico del ascenso fascista donde los roles quedan previamente determinados ${ }^{45}$. En breve, la diferencia entre uno y otro vínculo es el traspaso al campo de lo político.

La tarea que nos deja pendiente Lezra es cómo alterar esta relación de dependencia para la construcción de la República salvaje, considerando a la mordida tanto como un camino de salida como también el término del fascismo actual: "República salvaje, material, hace falta pensar o imaginar, la mordida anterior, el subjectum o el término de la mordida" ${ }^{46}$. El problema de la mordida entonces es pensar cuál es su término o la función que ella tiene en la axiomática capitalista como principio término-lógico que preserva las jerarquías dando la muerte (mors/dida). La mordida entonces no se representa, sino que se presenta en la materialidad del encuentro, dejando una marca sobre otro cuerpo para constatar que el pasado ha sido real. Sin embargo, existe una marcada diferencia entre la mordida que menciona Lezra, como "...mors-dida. Lo mutuo, lo compartido, lo que nos limita-deslimita, como el goce, la jouissanse. En tanto mors, muerte, no es común; en tanto mors siempre es sólo mía"47 y el pensar la mordida anterior que forma o subjetiva al sujeto del capital en su axiomática que establece y sutura la relación de producción como una despótica, "...como autoridad del capitalista, como poder de una voluntad ajena que somete a su objetivo la actividad de ellos" $" 48$.

No es novedad decir que, en reiteradas ocasiones, encontramos en los trabajos de Marx una caracterización monstruosa que él hace del capital, utilizando el categorial de la cultura gótica: en su obra abundan los hombres-lobos como las mesas danzantes. Sin embargo, estas imágenes están puestas ahí por una razón. Los monstruos (monstrum) tienen la función de mostrar (mostrare) y por ello advertir, los horrores del mundo presente y del futuro ${ }^{49}$. La forma monstruosa que toma el capital para Marx, en la inagotable sed de sangre de la clase burguesa, es la del vampiro ${ }^{50}$. El monstruo es la verdadera cara del capitalismo, mientras que él es el único vampiro de verdad ${ }^{51}$. Esto es más que una metáfora para explicar que las relaciones de producción capitalistas hacen a la composición de roles dependientes, haciendo que el proceso de convertir la potencia del tra-

\footnotetext{
Ibidem, p. 219. Aquí Lezra utiliza diferentes frases como ejemplo para enfatizar las relaciones a-políticas que ellas implican. Una es "Make America great again".

46 J. Lezra, República salvaje op. cit. p. 177.

47 Ibidem, p. 325

48 K. Marx, El capital Tomo I Vol. II, op. cit. p. 403.

49 A. Policante, "Vampires of Capital", Cultural Logic, 17, 2010, p. 3.

50 M. Neocleous "The Political Economy of the Dead", History of Political Though, 24, 4, 2003, p. 669. Como dijimos, esta imagen proviene de la cultura gótica muy presente en el contexto de Marx e incluso ya la había usado Engels en La situación de la clase obrera en Inglaterra. Usar al vampiro como metáfora de la relación de producción en su proceso de explotación es un lugar común y no una novedad, como podemos verlo en textos como "Vampiros" en el Diccionario filosófico de Voltaire o en el comic Fantomas contra los vampiros multinacionales de Julio Cortázar.

51 A. Policante op. cit. p. 17.
}

bajador en el acto del trabajo de las relaciones de explotación se iguale al de una clase que succiona el trabajo vivo de la otra. Al contrario de la clase aristocrática que no escatima en gastos improductivos, la clase burguesa descripta por Marx observa en todo gasto la cancelación de generar plusvalor a futuro, al mismo tiempo que su sed de hacerse de valor agregado es infinita. El capitalista burgués conforma y explota una específica forma de relación con su subditus para la producción de mercancías. Esto lo convierte en una clase parasitaria que vive de otros, que al mismo tiempo devela la narrativa capitalista al menos en dos elementos. El primero es que a pesar que el encuentro de los compradores y los vendedores de la fuerza de trabajo se establezca en un marco legal que los hace iguales como mencionamos anteriormente. Esta narrativa de la venta de la fuerza de trabajo libremente en el mercado, muestra un doble estándar de lo parasitario: mientras que una clase puede vivir parasitariamente del trabajo del obrero, esta relación se libra de cualquier elemento aleatorio al punto que se prohíbe que esa relación parasitaria no pueda ejercerse de forma opuesta.

La transformación de la organización del poder político, legal, jurídico, penal, entre otros, de lo que Foucault llama poder soberano al poder disciplinario, se encarga tanto de formar una clase como una subjetividad laboral, al mismo tiempo que disciplina reencausando las desviaciones al sujeto creado ${ }^{52}$. Para Foucault, el entramado institucional que desarrolla la política disciplinaria pretende la formación de un sujeto para el trabajo, para evitar la formación del peor terror del orden del trabajo: que un grupo o una clase social parasitaria que viva del trabajo de los otros, o sea, la vagancia, la pereza o la holgazanería. Esto hace que la relación parasitaria en las relaciones de producción del sistema capitalista sólo pueda ser de arriba para abajo, pero no al revés: el trabajador no puede vivir del trabajo de otro. Como dijimos anteriormente, y en la misma tónica de Althusser y Deleuze, lo que vemos es una relación de producción determinada y determinante que, a pesar del encuentro, se libera de toda aleatoriedad que pueda generar otro tipo de encuentros que devengan en la creación (política) de otro mundo.

Por otro lado, la imagen del vampiro tiene un valor simbólico en sí ya que, como menciona Mark Neocleous, Marx podría haber optado por otras figuras para metaforizar lo parasitario de esta relación: una sanguijuela, un parásito, un piojo o algo similar ${ }^{53}$. Sin embargo, es esta metáfora la que mejor describe las relaciones de autoridad entre los seres humanos, haciendo de la relación de producción entre explotador y explotado, una dialéctica con dientes ${ }^{54}$. Lo que queda implícito, y que se encuentra sistemáticamente ausente en los trabajos que problematizan lo monstruoso del capital en Marx, es que esta relación vampírica demanda la acción de una mordida específica de uno de sus integrantes al otro. La mordida vampírica penetra el cuerpo de quien la sufre,

\footnotetext{
2 M. Foucault, La sociedad punitiva, trad. H. Pons, Buenos Aires, Fondo de Cultura Económica, 2016, p. 140.

53 M. Neocleous, op. cit. p. 674

$54 \quad$ Ibidem, p. 677.
} 
traspasa el terminus del cuerpo del otro, lo posee para que deje de ser suyo al imponer un sentido y una mutilación necesaria para la producción capitalista. Se necesita marcar otro cuerpo, morderlo. De eso se trata su encuentro: de que un extremo del contrato igualitario marque el cuerpo del otro no sólo impidiendo una respuesta políticamente igualitaria como pretende la mordida entre amantes. En breve, se trata de marcar o de ser marcado. Ello pretende inhabilitar la apertura a la aleatoriedad para que ese encuentro sea o devenga en uno diferente en su reproducción. Podemos observar entonces dos resultados de esto. Por un lado, la problematización de la vida y la muerte está en la reproducción de los medios como de las relaciones de producción. Por el otro, cómo la praxis y la relación del trabajo componen la identidad y subjetividad del trabajador que refuerzan la inevitabilidad de este encuentro entre explotador y explotado en el mercado de trabajo, lo que para Franco "Bifo" Berardi demostraría la cooptación de su alma.

Como sabemos, en el mercado se produce el encuentro entre quienes venden y quienes compran mercancías. La particularidad del obrero es que vende la única mercancía que tiene: su fuerza de trabajo. "La fuerza de trabajo sólo existe como facultad del individuo vivo" ${ }^{55}$. Por lo tanto, el capitalista compra y consume actividad laboral como fermento vivo que el acto de la producción se vuelve trabajo trasladado a la mercancía, es decir, trabajo muerto. En esta línea, Marx dirá que el capital tiene en sí y para sí, un único impulso vital: el de valorizarse creando plusvalor, absorbiendo del obrero la mayor cantidad de plustrabajo que pueda, acumulándolo como trabajo muerto:

El capital es trabajo muerto que sólo se reanima, a la manera de un vampiro, al chupar trabajo vivo, y que vive tanto más cuánto más trabajo vivo chupa. El tiempo durante el cual trabaja el obrero es el tiempo durante el cual el capitalista consume la fuerza de trabajo que ha adquirido. Si el obrero consume para sí mismo tiempo a su disposición, roba al capitalista ${ }^{56}$.

El capitalista debe su riqueza a la acumulación de trabajo muerto. El consumo de la fuerza de trabajo se metaforiza entonces con la succión de la sangre que hace el vampiro al morder el cuello de su víctima. Ello materializa una contradicción: mientras el capitalista tiene una sed de sangre insaciable, tiene que garantizar la reproducción de quien hace el trabajo productivo. El capitalista no se puede dar el lujo de deshacerse de su súbdito como lo hiciera Saturno. Por el contrario, el capitalista debe garantizar su supervivencia para seguir succionando vida del explotado. El vampiro no se desprende de su víctima siempre y cuando haya un músculo qué explotar ${ }^{57}$. En esta delgada línea entre vida y muerte se organiza el modo de producción capitalista en pos de satisfacer su necesidad ilimitada de plustrabajo. El vampiro es la aristocracia convertida en sed de insaciable dominio capitalista del burgués, que vive de la acumulación del trabajo vivo del obrero. Pero su límite no será

\footnotetext{
5 K. Marx, El capital Tomo I Vol. I op. cit. p. 207

56 Ibidem, pp. 279-80

57 Ibidem, p. 364.
}

el cuerpo, sino que esta axiomática también apunta a la posesión del alma.

Para Franco Berardi, el devenir de las relaciones de producción que derivan en una sofisticación técnica produce una explotación todavía mayor en el trabajador cognitivo del siglo XXI. Ello tiene como consecuencia que el trabajador posmoderno, sea cooptado no sólo de su cuerpo como lo hace el vampiro con su víctima, sino también de su alma al ser el trabajo vivido como una auto-realización de la libertad ${ }^{58}$. En otras palabras, el trabajo industrial y su axiomática alienan al trabajador de su trabajo en su propia "falta de autorrealización" lo que da muerte a la autonomía del trabajador frente al dominio del capital sobre el trabajo: "Esta realización del trabajo aparece en el estadio de la Economía política como desrealización del trabajador, la objetivación como pérdida del objeto y servidumbre a él, la apropiación como extrañamiento, como enajenación" ${ }^{\circ}$. Sin embargo, para Berardi, la transformación neoliberal del trabajo desmaterializa las formas de explotación industriales, produciendo una nueva relación de explotación enfocada en la del trabajador cognitivo-precarizado. Esta nueva relación de explotación no es más vivida como desrealización como apuntara Marx, sino como auto-realización, lo que denota no sólo una cooptación del cuerpo sino también del alma ${ }^{61}$. El alma aquí es entendida desde la tradición atómico-materialista de Lucrecio y Epicuro, siendo ella el clinamen o el ángulo que inclina a los cuerpos los-unos-con-los-otros. Ella hace que los cuerpos se unan en un mismo ritmo o frecuencia, lo que permite el juego de seducción, que es la relación con lo otro ${ }^{62}$. El alma no devela el ser (sein) sino el sercon (mitsein) los otros en el mundo. Pone a los cuerpos en contacto haciéndolos afines, lo que conforma un tejido de las fuerzas libidinales que negocian su relación con los otros y con el mundo, que necesita constantemente reanudarse ya que, como toda materia, también se extingue ${ }^{63}$.

Para Berardi, la transformación del trabajo de la era neoliberal disuelve la organización industrial para crear formas más efectivas de dominio que precarizan el trabajo, entre otras consecuencias ${ }^{64}$. La más evidente es la metamorfosis de la ética laboral que hace a un sujeto predispuesto a la cooptación del alma que, al imponérsele una economía libidinal, fija las relaciones aparentando ser naturales y eternas, despolitizándolas. Este orden des-erotiza el alma encauzando al deseo al trabajo y des-diferenciando su ética con la política, haciendo que

\footnotetext{
58 F. Berardi, The Soul at Work, trad. F. Cadel y G. Mecchia, Los Angeles, Semiotext(e), 2009. p. 14

59 C. Casanova, Estética y Producción en Karl Marx, Santiago de Chile, Metales Pesados, 2016, p. 8.

60 K, Marx, Manuscritos de Economía Política, Madrid, Alianza, 2003, p. 106.

1 F. Berardi., op. cit., p. 13

62 Ibidem, pp. 9, 115.

63 J. Lezra, República salvaje op. cit., p. 64.

64 Subempleo, violencia, emigración masiva, violencia contra la mujer, precarización, desempleo, etc. Cf. F. Berardi, The Soul at Work, op. cit. Cf. también de Franco Berardi, Héroes: asesinato masivo y suicidios, trad. P. Cáceres, Madrid, Akal, 2015; y La fábrica de la infelicidad: nuevas formas del trabajo y movimiento global, trad. M. Aguilar Hendrickson y P. Amigot, Madrid, Traficante de sueños, 2003.
} 
las relaciones laborales y políticas sean lideradas por un totalitarismo tiránico ${ }^{65}$. Es por esta razón que Berardi se pregunta cómo entender la transformación de la popularidad de la idea de la abolición del trabajo a fines de los años sesenta y principios de los setenta ${ }^{66}$, a pelear por trabajar más, sin poner esta praxis en cuestionamiento. Sin embargo, podemos tomar esto como la consecuencia de la inmanencia de la axiomática de las relaciones de producción. Lo que nos recuerda Marx siguiendo la misma lógica que Lucrecio, es que esta relación de explotación como la conocemos no es más que el devenir de encuentros aleatorios a los que Marx figura de guerra civil: "La fijación de una jornada laboral normal es por consiguiente, el producto de una guerra civil prolongada y más o menos encubierta entre la clase capitalista y la clase obrera" ${ }^{67}$. El contrato de la relación de explotación es sólo la consecuencia de devenires de encuentros aleatorios, de límites negociados y fijados por la fuerza. La axiomática capitalista es entonces el resultado de tensiones resueltas, de un negotium ya hecho: "El salario está determinado por la lucha abierta entre el capitalista y obrero" que "hace al obrero cada vez más dependiente del capitalista" ${ }^{68}$. Lo que dice Berardi entonces no es nuevo, sino que siempre ha estado ahí según Marx, ya que la sed vampírica del capitalista hace que "...el trabajo vivo se presenta como simple recurso para valorizar el trabajo objetivado, muerto, para impregnarlo de un soplo vivificante y perder en él, su propia alma"69. Por lo tanto, el proceso asalariado de explotación que se metaforiza con la relación vampírica entre explotador y explotado, es solo un encuentro que es posible gracias al alcance de una madurez del sistema de producción capitalista. El trabajador es arrojado a este encuentro ya históricamente maduro, no teniendo más opciones que sucumbir a esta relación del robo de su vida por parte del capitalista, cuando se encuentra aislado. El trabajo asalariado existe entonces porque es la forma de producir plustrabajo. Al mismo tiempo, esta madurez de las condiciones objetivas de explotación, permiten la sofisticación de leyes externas a la relación de explotación que solidifican esa relación como, por ejemplo, las normas de competencia que terminarán siendo coercitivas ${ }^{70}$. Por lo tanto, llegamos a la conclusión que el movimiento inmanente de la axiomática capitalista del trabajo intensifica las relaciones de producción que forma un sujeto trabajador -o ser-para-el-trabajo- cuya intensificación

\footnotetext{
F. Berardi, op. cit. p. 80.

66 Por ejemplo, el Operaismo italiano, la revista Zerowork en Estados Unidos, etc.

${ }_{67}$ K. Marx, El capital Tomo I Vol. I. op. cit. p. 361.

68 K. Marx, Manuscritos de Economía Política, op. cit. pp. 51, 58.

$69 \mathrm{~K}$, Marx, Elementos fundamentales para la crítica de la economía política (Grundisse) Vol I, Buenos Aires, Siglo XXI, 1971, p. 422. A la misma conclusión llega también más tarde Marx en el mismo texto: "En el capital se pone la perennidad del valor (hasta cierto punto) en la medida en que aquél se encarna en las mercancías perecederas, adopta su forma, pero, asimismo las modifica; alterna entre su forma perenne en el dinero y su forma perecedera en las mercancías; la perennidad es puesta como lo único que ella puede ser: transitoriedad que transcurre, proceso, vida. Pero esta facultad, el capital sólo la adquiere succionando continuamente, como un vampiro, el trabajo vivo a título de sustancia que la anima". K, Marx, ibidem, p. 162.

70 K. Marx, El capital Tomo I Vol I, op. cit. p. 326.
}

ha pasado de la des-realización a la auto-realización en la cooptación de su alma.

El problema de fondo termina siendo el mismo al que apunta República salvaje: ¿cómo pensar otro tipo de relaciones, otro republicanismo, otra institucionalidad defectiva, que transforme a ese sujeto en potencia? ${ }^{71}$ En otras palabras, como nos indica Lezra en $\mathrm{On}$ the $\mathrm{Na}$ ture of Marx's Things, "el trabajo se ha incorporado a su sujeto: el primero es materializado, el segundo transformado. Lo que aparecía en el obrero como movimiento, ahora aparece en el producto, como cualidad fijada sin movimiento" (mi traducción) ${ }^{72}$. Por lo tanto, si la conformación del sistema capitalista convierte la potencia del trabajador en acto, de lo que se trata no es de volver el acto en potencia, sino de una forma de devenir en el que el acto esté habitando y habitado por la posibilidad de la dislocación, imposibilitando la clausura de la potencia y así poder abrirse a lo aleatorio de las relaciones políticas $^{73}$. Es crucial entonces volver a la idea de cómo hacer aparecer lo aleatorio del clinamen en una relación que pretende abolirlo. En el sentido político, Marx es claro al intentar diferenciar estrategias que alteran, de las que refuerzan las relaciones de explotación. En particular, en el primer volumen de El capital, Marx se enfoca en el contrato de trabajo y la duración de la jornada laboral: "La prolongación de la jornada laboral más allá de los límites del día natural, hasta abarcar las horas de la noche, sólo actúa como paliativo, mitiga apenas la sed vampírica de sangre viva de trabajo" "74. La extensión de la jornada laboral aplaca temporalmente la sed vampírica, al mismo tiempo que el acortarla no interrumpe la axiomática, ya que se puede balancear esa pérdida de plusvalía al intensificar el ritmo de producción, por ejemplo. Nos resulta evidente que el problema de fondo termina siendo cómo hacer de la emancipación de este sujeto del trabajo que, como dice Carlos Casanova, se encuentra declinado a ser un ser sin obra o una cifra de lo impropio, que se encuentra fuera-de-cuenta ${ }^{75}$. Esto nos dice que el desafío que tiene la propuesta de Lezra en República salvaje será también el de pensar y formar relaciones de producción que estén más allá de la axiomática laboral capitalista, de pensar la reproducción social más allá de la explotación. En breve, de abolir la relación vampírica y su mordida como condición de reproducción de la vida.

Según la interpretación de Casanova de Los manuscritos...de Marx, la alienación da vida a las relaciones de producción que se manifiesta en la alienación de los sentidos y de la potencialidad de poder enfrentarse a poderes extraños ${ }^{76}$, lo que también imposibilita al obrero de crear un nuevo común. El sujeto del capital se encuentra alienado en sus sentidos, habitando un devenir impropio.

\footnotetext{
J. Lezra República salvaje op. cit. p. 284.

72 J. Lezra, On the nature of Marx's Things, op. cit. p. 3. La siguiente es la cita original: "Labour has incorporated itself with its subject: the former is materialized, the latter transformed. That which in the labourer appeared as a movement, now appears in the product, as fixed quality without motion".

73 C. Casanova op. cit. pp. 10-11.

74 K. Marx, El Capital Tomo I Vol I op. cit. pp. 308-9.

75 C. Casanova, op. cit. p. 23.

76 Ibidem, pp. 24-5.
} 
El trabajador se encuentra enajenado de sus sentidos, por lo que su emancipación depende de la transformación de un proceso práctico-sensible en su declinación social, que queda imposibilitado si no se crea un nuevo común y no se destruye la propiedad privada. Sin embargo, no existe lo común sin producción. Por lo tanto, la emancipación comunista así entendida, depende de una revolución de los sentidos que genere una transformación del régimen de lo sensible. Ella provocaría la desviación de los átomos: "En la desviación -escribe Marx- está representada la verdadera alma del átomo" "77. En otras palabras, el clinamen des-enlaza el encuentro de la mutua dependencia de la axiomática capitalista, liberando a los sentidos haciendo del acto del trabajo derive en un gesto asociativo, aleatorio, comunal, solidario e indeterminado que hace que el sujeto explotado recupere su alma. Esto produce un doble movimiento. Por un lado, se propone una nueva relación con los otros, una nueva composición de la relación del ser-en-común, metaforizado con la mordida entre amantes o defectiva, que suplantaría la mordida vampírica de la axiomática capitalista. Dicho de otro modo, lo salvaje de la república según Lezra, demanda este cambio onto y odontológico de lo común. Por otro lado, esto no sólo haría recuperar el alma del sujeto explotado, perdida en la inmanencia de la axiomática capitalista. La nueva apertura para el encuentro aleatorio, como dijo Malebranche, también tiene un aspecto formativo ya que prepara el alma para una nueva lluvia. El encuentro entonces abre la posibilidad del devenir de encuentros materiales que, en su propia aleatoriedad, va formando constantemente lo que Lezra ha llamado República salvaje. Esta será una república que va renegociando los términos comunes constantemente, desordenando los roles entre quienes mandan y quienes obedecen como lo hace la división del trabajo.

Como propone Lezra, lo que debemos repensar es un nuevo republicanismo a partir de la ontología de lo común, es decir, la de la ontología de las relaciones sociales. Para ello, no basta sólo con denunciar el disciplinamiento histórico de los sentidos como dice Casanova, sino también proponer -como hace Lezra- una forma, una manera o una práctica de las relaciones sociales que vuelvan defectivas las relaciones de producción como las conocemos. En esta línea, debemos lograr separar reproducción de explotación. En otras palabras, hay que volver defectiva la mordida del vampiro para convertirla en una mordida que nos abra a lo salvaje. Por lo tanto, la propuesta de la construcción de la República salvaje de Lezra, no se limita sólo a la apertura del encuentro, sino que ello también demanda suplantar las relaciones de producción como las conocemos. La República salvaje no puede realizarse sin ese necesario abandono, lo que significa al mismo tiempo, el abandono de la concepción moderna del trabajo. Este es otro de los múltiples desafíos que demanda la superación del ascenso del fascismo: el transformar lo vampírico a lo salvaje.

\section{Bibliografía}

Althusser, L., Para un materialismo aleatorio, trad. P. Férnandez Lira, L. Alegre Zahonero y G. González Diéguez, Madrid, Arena, 2002.

-, "The Underground current", Philosophy of the Encounter, trad. G. M. Goshgarian, New York, Verso, 2006, pp. 163-207.

-, On Reproduction, New York, Verso, 2014.

Berardi, F., Héroes: asesinato masivo y suicidios, trad. P. Cáceres, Madrid, Akal, 2015.

-, La fábrica de la infelicidad: nuevas formas del trabajo y movimiento global, trad. M. Aguilar Hendrickson y P. Amigot, Madrid, Traficante de sueños, 2003.

-, The Soul at Work, trad. F. Cadel y G. Mecchia, Los Angeles, Semiotext(e).

Casanova, C., Estética y producción en Karl Marx, Santiago de Chile, Metales Pesados, 2016.

Deleuze, G., Derrames I: entre capitalismo y esquizofrenia, Buenos Aires, Editorial Cactus, 2013.

Foucault, M., La sociedad punitiva, trad. H. Pons, Buenos Aires, Fondo de Cultura Económica, 2016.

Lezra, J., On Nature of Marx's Things, New York, Fordham UP, 2018.

-, República salvaje, Santiago de Chile, Ediciones Macul, 2019.

-, "Odontologies", en A. Weiner y L. Kaplan (eds.), Madness, Melancholy and the Limits of the Self Graven Images 3, Wisconsin, University of Wisconsin Press, 1996, pp. 92-102.

-, "Relation", en A. Stoler, S. Gourgouris, J. Lezra (eds.), Thinking with Balibar: a Lexicon of Conceptual Practice, New York, Fordham UP, 2020, pp. 211-29.

Mark N., lo tomucleous “The political Economy of the Dead: Marx's Vampires".

Marx, K., Manuscritos de Economía Política, Madrid, Alianza, 2003.

-, El capital Tomo I Vol. I, Iztapalapa, Siglo XXI, 2018.

-, El capital Tomo I Vol. II, Iztapalapa, Siglo XXI, 2017.

-, "Tesis sobre Feuerbach" https://www.marxists.org/espanol/m-e/1840s/45-feuer.htm

-, Elementos fundamentales para la crítica de la economía politica (Grundisse) Vol I, Buenos Aires, Siglo XXI, 1971.

Mezzadra, S., La cocina de Marx, trad. D. Picotto, Buenos Aires, Tinta Limón, 2014.

Motte, W., "Clinamen Redux" Comparative Literature Studies, 3, 4, 1986, $263-81$.

Neocleous, M., "The Political Economy of the Dead" History of Political Though 24(4), 2003, pp. 668-84.

A. Policante, "Vampires of Capital" Cultural Logic, 2010, 1-20.

Villalobos-Ruminott, S., Asedios al fascismo, Santiago de Chile, DobleAEditores, 2020.

\footnotetext{
Ibidem, p. 75 .
} 